\section{Rethinking debt by its limits}

Bertram Lomfeld

Free University Berlin, Germany

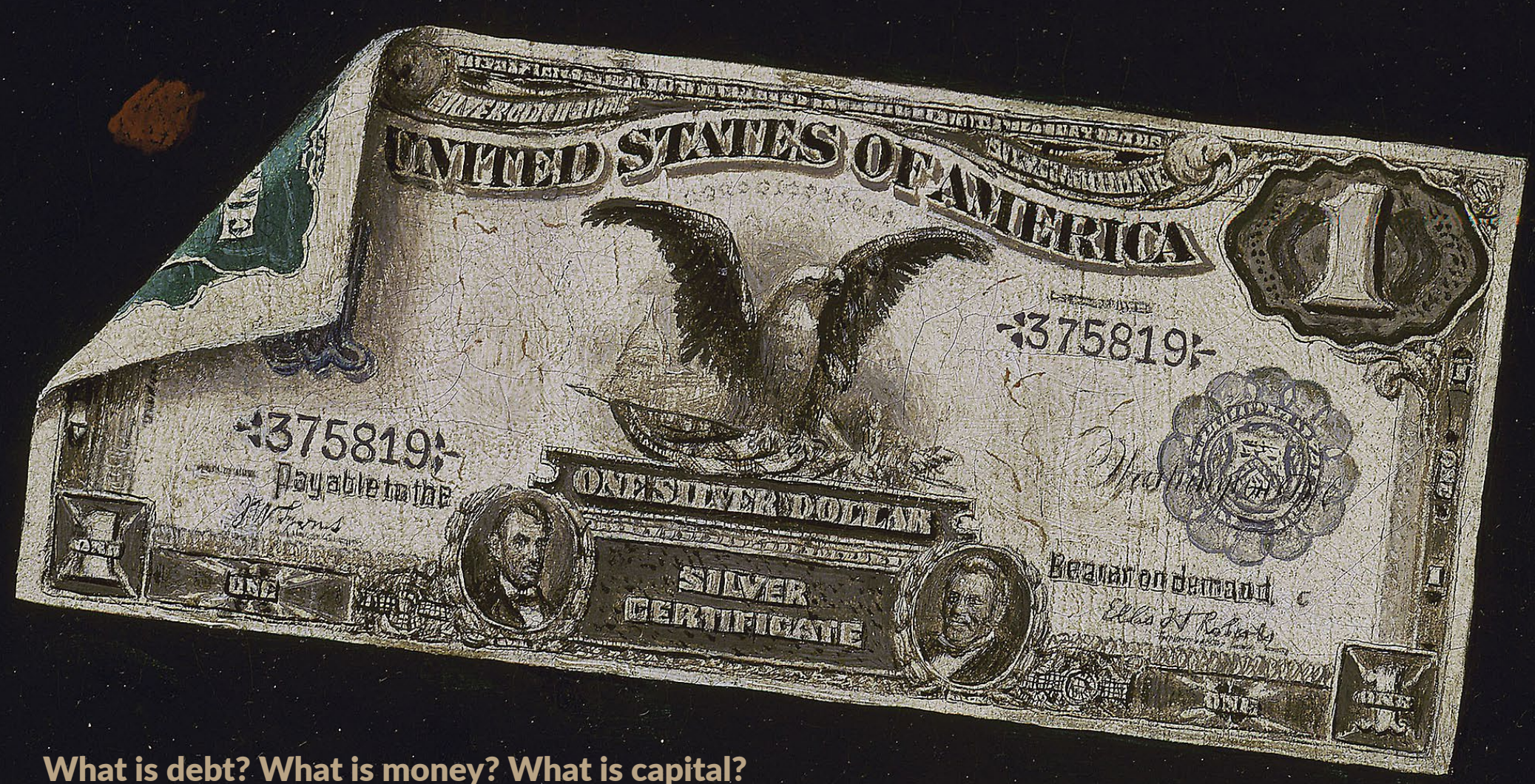

In which way is our capitalist economic system built on debt? Does debt force unsustainable growth and deepen inequality? Could insolvency law reshape debt as a reflexive social medium? How to model democratic debt restructuring?
Debt as a primary

economic medium

If money makes the world go 'round, debt speeds the turn. But what is debt? Debt and credit are social bonds that enable logical pair of formalised exchanges. The creditor gives something to the debtor, who owes the creditor and promises to (ive owes the creditor and pronises to give somethe back ter. Essentially, claluted in money, to pay back whe ther owe. Adding regur interest rates, debt buys time.

\section{DEBT = PAY TIME}

Figure 1: The form of debt.

In legal terms, both parties (creditor an debtor) enter into a binding contract. If the contractual object is money, the bond is called debt. From an analytical point of view, all time-delayed transactions are credits or debts. The central medium for exchanging, measuring and memorising debt and transactions, in general, is money. Even money is credit, promising collective and public future acceptance. Stock markets, cryptocurrencies and decentralised finance add private collective credit systems.

Debt-based reconstructions hold true for all capital circulation investing, e.g. land, material resources or funds into an economic endeavour to make a promisin future profit. The primary economic medium in capitalism is debt with basic monetary code of 'to pay or not to pay'. Here, the term 'liquidity' enters the stage to classify different sorts of debt, money and capital. One subliminal objective of the project is to outline the basic constitutional legal mechanisms of collective credit systems in general.

\section{The global debt problem}

Credits serve as investments in growth for all.economic actors: firms, consumers and states. Present growth is financed by debt and refunding debt is based on future growth. Debt is a core element of the perpetual growth logic which is a central threat to sustainable development.

Debt bubbles cause financial and economic instabilities, as illustrated by the 2008 global financial crisis. The natural limits to growth on our planet (e.g. climate change) are not reflected in the economic medium. Neither is the rising distributional inequality around the globe and within nearly every national society. Both democratic governance and actors' autonomy suffer from the structural power of heavy economic debt.

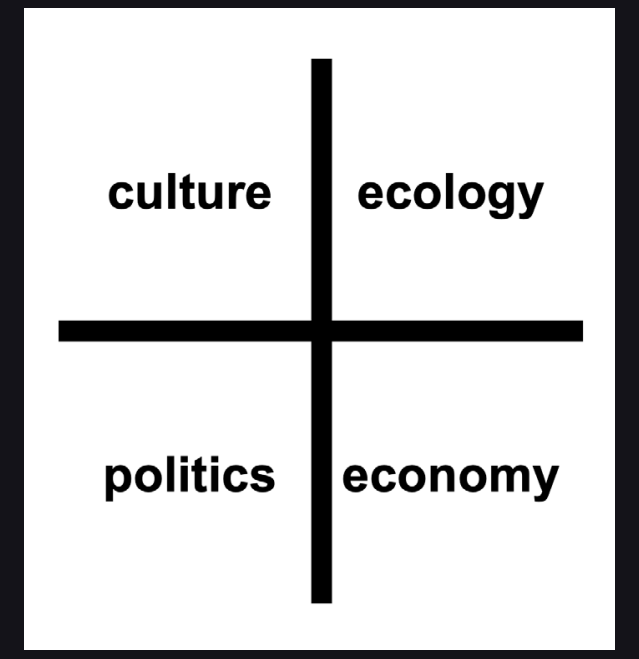

Figure 2: Functional social spheres.

In short, an unlimited and reductionist financial conception of debt drives economic, ecological, cultural and political unsustainability. Decoupled financial markets (e.g. derivative trading), imperialistic debt politics or massive public and private debts (e.g. as a reaction to pandemic-driven recession) provide further leverage to a vicious global debt cycle.

The project's central research question is: How can we rethink debt as a more sustainable and integrative social medium? 


\section{A discoursive normative} grammar (DNG) for resolvency

The legal core of the project is a comparative analysis of insolvency regulations for corporations, consumers analyses compare and index crucia 'insolvency factors' (e.g. opening criteria, priorities, discharge, restructuring decision procedures) worldwide. Followup qualitative discourse analyses legislative motives, judicial opinion and insolvency scholarship in selected legal orders identify the nelected beckground reasons for the specifc fackground rasons for the speciffc will be reconstructed within a 'deasons' will be reconstructed within a discours nomative gramnar' (DNG, cf. Figu 3) of fundamental legal values, which mostly coincice with diferent paradign of poltical economies (varieties capitalism, cr. Frgure 3). The objective structure for det resal argumentative incorporate diverse normative reason from corporate, consumer and sovereig insolvency theories across differe jurisdictions. The pluralist frame allows comparing and classifying national and international insolvency and restructurin regulations and integrating further soci values, i.e. a wider 'resolvency DNG.

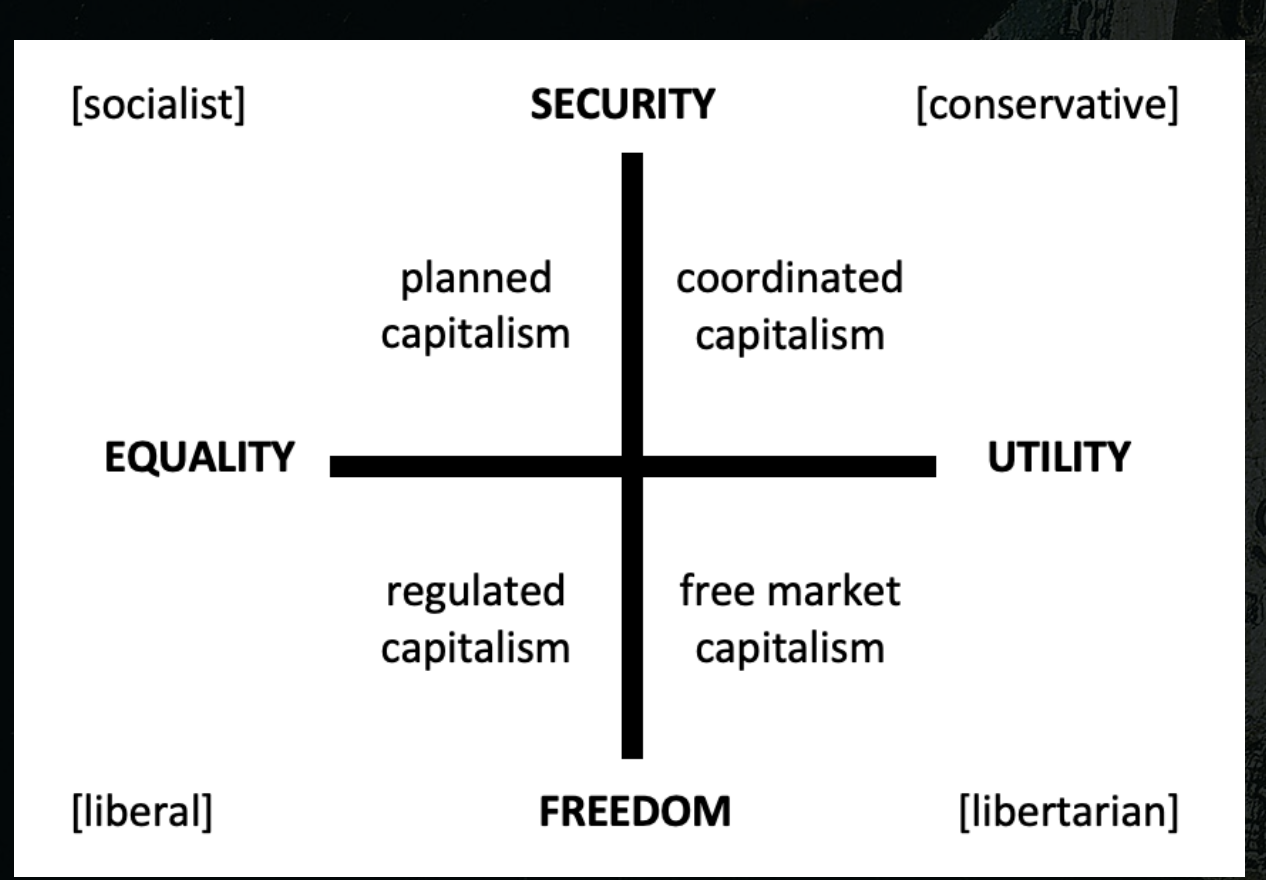

Figure 3: Discoursive normative grammar and varieties of capitalism.
Democratic debt restructuring RESOLVENCY team and cooperation

If credits do not lead to expected growth, Apart from the professorial lead, the social confilicts emerge. Really 'resolving' core project team consists of three legal debt conflicts requires not only the PhD students with multidisciplinary and consent of creditors about the distribution multiple language capacities. Each $\mathrm{PhD}$ of remaining assets but a collective student will focus on different insolvency procedure including debtor and all other and restructuring areas of corporate debt. private (employees, inhabitants) and public consumer debt, and sovereign state debt. (communities, environment) interests The methodology and evaluation of the involved The project tries to model quantitative analyses and the experiments different legal designs of such democratic are co-led by an economic postdoc. debtdeliberation procedures, which will be Three student researchers from different evaluated in economic game-theoretical disciplines and national backgrounds will experiments. On a substantial level, the support the core research team Academic proiect strives to outline some measure or coopertion partners around the slobe

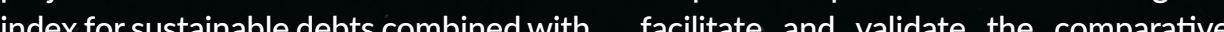
models on how to incentivise them by anases. Workshops with intore reshaning how to incentive then by ans essumptions of this interrelation and ex eviluate project results and suats ante effects on credit inake vill aeth be tect in cxperiments. The ultimate be tested in experinents. The ultwate (RE:DEBT) which links social re-entries in collective restructurng procedures with a

RE:DEBT

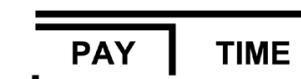

\section{ME}

social and sustainability sciences. On an academic level, the theoretica elaboration of the resolvency paradigm could stimulate new legal readings of insolvency laws as a regulatory instrument. The primary economic medium hypothesis and outcomes on ex ante effects of insolvency law are of utmost importance for economic debt theory. The interdisciplinary reconstruction of debt and collective debt systems (including money) might influence social and sustainability science models.

Regarding potential practical impact, current European unification attempts of insolvency law will surely profit from the project's global comparative analyses and political economy classification. International financial institutions (e.g. IMF, World Bank) could be interested in substantial indexes or measurements of sustainable debt. Resolvency procedura designs and respective model collective action clauses affect political initiatives and existing institutions (e.g. ESM) on sovereign debt crisis. Democratic debt governance, including collective To take the turn, sustainable development restructuring procedures, touch needs mechanisms to limit debt and its not only worldwide plans for pre- negative externalities. Reflexive debt insolvency restructuring laws but also governance might prevent the world decentralised governance visions of new from falling out. autonomous collective debt systems like cryptocurrencies.

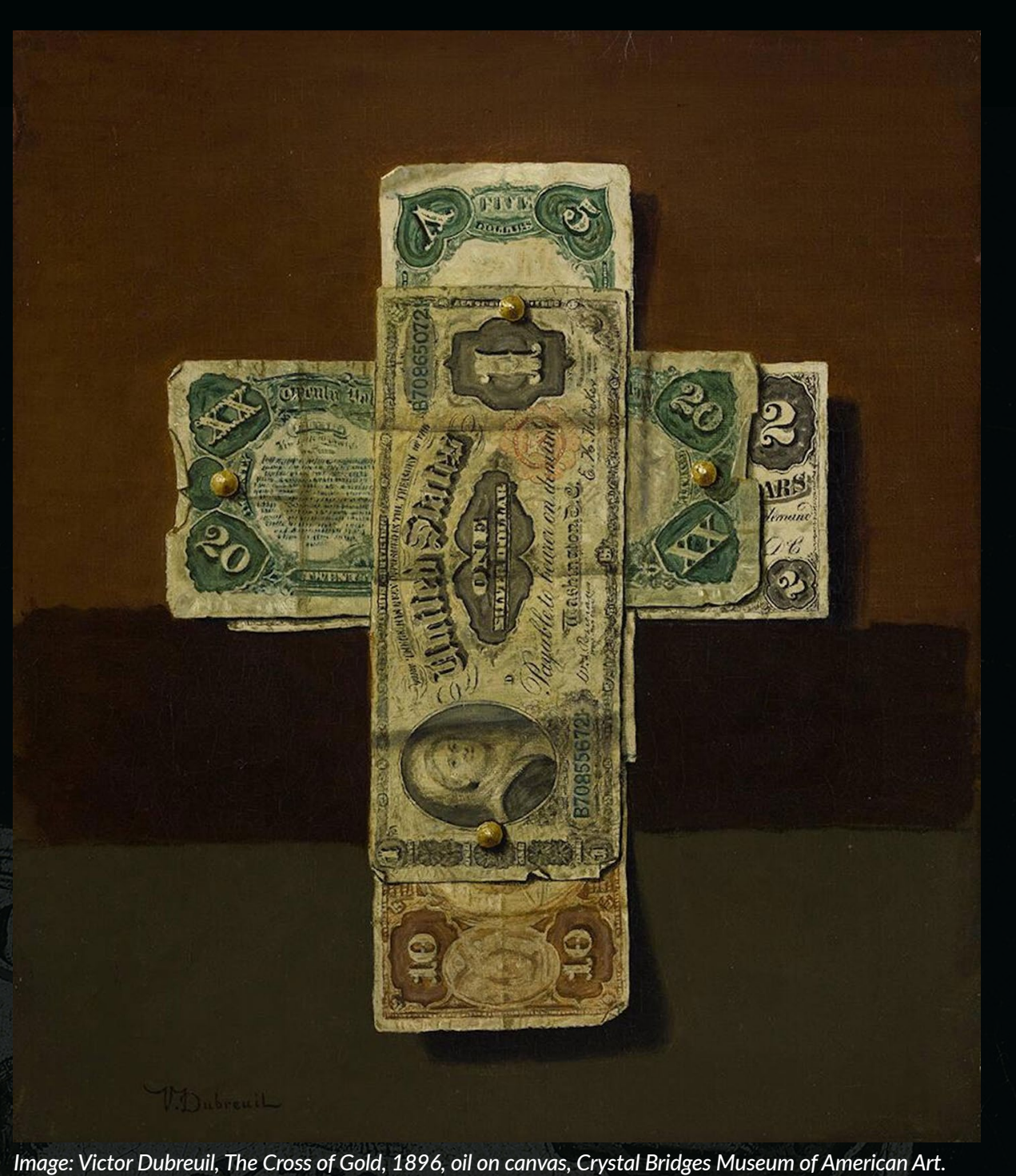

Image: Victor Dubreuil, The Cross of Gold, 1896, oil on canvas, Crystal Bridges Museum of American Art.

RESOLVENCY project wants to reveal the full potential of insolvency law to regulate and constitute debt markets.
PROJECT NAME

RESOLVENCY: A Global Theory of Reflexive Debt

PROJECT SUMMARY

The multidisciplinary ERC starting grant project RESOLVENCY aims to shape a new 'reflexive' debt paradigm by reframing insolvency law as democratic debt
restructuring, including sustainable debt restructuring, including sustainable debt
standards. Key methods of the project are standards. Key methods of the project are legal analyses using the novel discoursive normative grammar (DNG) approach, and exploratory procedural design models. PROJECT LEAD

Prof. Dr Lomfeld studied law, philosophy and political economy at the universities Vienna and obtained his PhD at Frankfurt University. He is currently professor for private law and the foundations of law at ree University Berlin. He held visiting positions at, among others, Columbia Law and was appinted to the Europen Lew and was appointed to the European L

\section{PROJECT PARTNERS}

The RESOLVENCY project is hosted at Free University Berlin. Its academic cooperation for the global comparative approach School, CUPL Beijing Sciences Po Paris, Copenhagen and Stockholm University,
European University Institute and MaxEuropean University Institute and Max Law.

CONTACT DETAILS

Prof. Dr Bertram Lomfeld

Free University Berlin, Van't-Hoff-Straße 8

14195 Berlin, Germany.

용 +493083855915

mail@resolvency.eu

(1) www.resolvency.eu

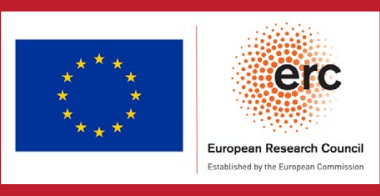

FUNDING

This project has received funding from the European
Research Council (ERC) under the European Union's programme under grant agreement №.950427. 